\title{
Training in and Experience with Endobronchial Ultrasound
}

\author{
Christina R. Bellinger ${ }^{a}$ Arjun B. Chatterjee ${ }^{a}$ Norman Adair $^{a}$ Tim Houle ${ }^{a}$ \\ Irtaza Khan $^{\mathrm{b}}$ Edward Haponik ${ }^{a}$ \\ ${ }^{a}$ Department of Pulmonary/Critical Care, Wake Forest Baptist Health, and ${ }^{\text {b }}$ Salem Chest, Winston Salem, N.C., USA
}

\section{Key Words}

Adequate specimen sampling · Endobronchial ultrasound . Lymphadenopathy · Procedural yield · Transbronchial needle aspiration

\begin{abstract}
Background: Diagnosing mediastinal and hilar lymphadenopathy and staging lung cancer with endobronchial ultrasound (EBUS)-guided transbronchial needle aspiration (TBNA) are on the rise, but uncertainty surrounds the optimal number of cases needed to achieve acceptable yields. $\mathbf{O b}$ jectives: To determine the threshold at which EBUS-TBNA reaches adequate yields among trainees and skilled bronchoscopists. Methods: We reviewed all EBUS-TBNAs performed at our medical center since implementing the use of EBUS $(n=222)$. Results: EBUS-TBNAs were performed in 222 patients (344 nodes). The percentage of adequate specimens sampled (diagnostic specimens or nodal tissue) rose from $66 \%$ in 2008 to $90 \%$ in $2012(p<0.01)$ and cancer yield improved from 34\% in 2008 to $48 \%$ in 2012 ( $p<0.01$ ). Attending physicians who performed an average of more than 10 procedures per year had higher yields compared to those who performed fewer than 10 procedures per year (86 vs. $68 \%, p<0.01)$. The yield of trainees also improved with every
\end{abstract}

10 procedures $(79,90$ and $95 \%, p<0.001)$ and that of attending physicians with experience ( $1-25$ procedures: $78 \%$ yield, $26-50$ procedures: $87 \%$ yield and $50+$ procedures: $90 \%$ yield; $\mathrm{p}<0.01$ ). Among trainees, failure rates declined steadily. Conclusion: EBUS-TBNA yield (malignant and benign) increases with increasing experience amongst experienced bronchoscopists and trainees as early as the first $20-25$ procedures. Pulmonary trainees had a rapid decline in failure rates. These findings suggest that in an academic environment a minimum of $20-25$ procedures is needed to achieve acceptable yields.

(c) 2014 S. Karger AG, Basel

\section{Introduction}

Endobronchial ultrasound (EBUS)-guided transbronchial needle aspiration (TBNA) is an increasingly effective method for sampling mediastinal and hilar lymph nodes $[1,2]$. Although primarily employed for lung cancer staging, this technology is also capable of diagnosing both benign and malignant lung node pathologies. Yields of EBUS-TBNA vary from 89 to $96 \%$ at skilled centers [3-6].

The learning curve for this relatively new diagnostic tool has not been clearly delineated. The American Col-

\section{KARGER}

E-Mail karger@karger.com

www.karger.com/res
C 2014 S. Karger AG, Basel

0025-7931/14/0886-0478\$39.50/0
Christina R. Bellinger, MD

Department of Pulmonary/Critical Care

Wake Forest Baptist Health

Medical Center Boulevard, Winston Salem, NC 27157 (USA)

E-Mail cbelling@wakehealth.edu 
lege of Chest Physicians recommends 50 procedures for competency [7], but this recommendation was made for radial EBUS before real-time linear EBUS became widespread. Kemp et al. [8] performed a cusum analysis of 500 EBUS-TBNAs performed by five operators. The speed of attaining high yields ranged from immediately to not even within the first 100 procedures. An Australian study found that diagnostic sensitivity increased from $60-80 \%$ in the first 20 cases to $92-93 \%$ after 20 cases [9]. A group of thoracic surgeons found that their diagnostic accuracy improved markedly (from 50 to $95.6 \%$ ) after just 10 procedures [10]. Another surgery group reduced false-negative and nondiagnostic samples to $<10 \%$ after 22 cases [11]. Most recently, Wahidi et al. [12] noted that after a didactic curriculum, simulation practice and 13 procedures, trainees were able to navigate the airways, identify the lymph node of interest and perform successful EBUS-TBNA. With such variability, it is no wonder the debate over what number is needed to achieve proficiency continues $[13,14]$ and whether that number differs between trainees and attending physician bronchoscopists. To address this concern, we evaluated the learning curve of EBUS at an academic teaching institution.

\section{Methods}

\section{Study Design}

Following approval from the Institutional Review Board at Wake Forest University (ID IRB00013684), we reviewed EBUS procedures performed at Wake Forest Baptist Health since implementing its use in 2008 and extending over a 5-year period. We reviewed medical records with regard to patient age, gender, sedation used, procedure time, recovery time, diagnosis and attending and trainee bronchoscopist participation.

\section{Methods}

EBUS-TBNA was performed using an Olympus ${ }^{\circledR}$ BF-Convex Scope XBF-UC160 F-OL8 with a 22-gauge needle or Pentax ${ }^{\circledR}$ Convex Scope EB-1970UK with a 22-gauge cytology needle. Attending physicians were experienced bronchoscopists (mean experience: 13 years), many with extensive conventional TBNA (cTBNA) experience [15]. Moderate sedation employed titrated doses of fentanyl and midazolam. General anesthesia involved either a laryngeal airway or endotracheal tube as determined by the bronchoscopist and anesthesiologist. Needle aspirates were prepared in the bronchoscopy suite and rapid on-site cytology was used. If the sample was likely non-small cell lung cancer, then nodal survey and staging was performed by sampling according to the 7 th edition of the TNM staging [16] (N3 then N2 then N1) followed by a cell block to provide additional material for immunohistochemical staining and subclassification. Malignancy yield was defined if lung or metastatic cancer was described by pathology. Adequate
Table 1. Patient and bronchoscopy characteristics

\begin{tabular}{lc}
\hline Procedures, $\mathrm{n}$ & 222 \\
Nodes, $\mathrm{n}$ & 344 \\
$\quad$ Per procedure & 1.5 \\
Patient age (mean \pm SD), years & $63 \pm 12$ \\
Females, \% & 41 \\
Outpatients, \% & 83 \\
Sedation, \% & \\
$\quad$ General anesthesia & 69 \\
$\quad$ Moderate sedation & 31 \\
Duration, min & \\
$\quad$ Anesthesia & \\
$\quad$ Procedure & $84 \pm 23$ \\
\end{tabular}

specimens encompassed all malignancy, lymph tissue or granulomas (in patients with a final clinical diagnosis of sarcoidosis).

Trainees of all levels were allowed to perform EBUS. They had no prior EBUS simulation training but had attended a 1-day general bronchoscopy course. An advanced bronchoscopy fellow, who focuses on additional training in advanced diagnostic bronchoscopy, is present in the majority of cases. Often, the fellow(s) perform the entire procedure unless difficulties occur requiring the attending bronchoscopist to take the instrument.

\section{Analyses}

Analyses were performed comparing EBUS-TBNA yield by year, lymph node location, operator experience and type of sedation. Results are presented as percentages and means \pm SD. Continuous variables were compared among groups using ANOVA models and, where a signal was present, groups were compared with Wilcoxon tests. Nominal variables were analyzed using $\chi^{2}$ tests for association followed by nominal logistic evaluation when applicable. Results were considered significant when $\mathrm{p} \leq 0.05$.

\section{Results}

\section{Patient Demographic Characteristics}

Between January 2008 and December 2012, a total of 222 EBUS-guided bronchoscopies were performed targeting 344 nodes. Mean patient age was $63 \pm 12$ years and the majority of patients were male (59\%; table 1$)$.

\section{Bronchoscopy Characteristics}

Typically, procedures were performed in an outpatient setting (84\%). With progressive institutional experience, moderate sedation was replaced in favor of general anesthesia (2008: $86 \%$ moderate sedation vs. $14 \%$ general anesthesia, 2012: $2 \%$ moderate sedation vs. $98 \%$ general anesthesia, $\mathrm{p}<0.001)$. Over the course of experience, there was no difference in anesthesia time (2008: mean $84 \pm 22$ 


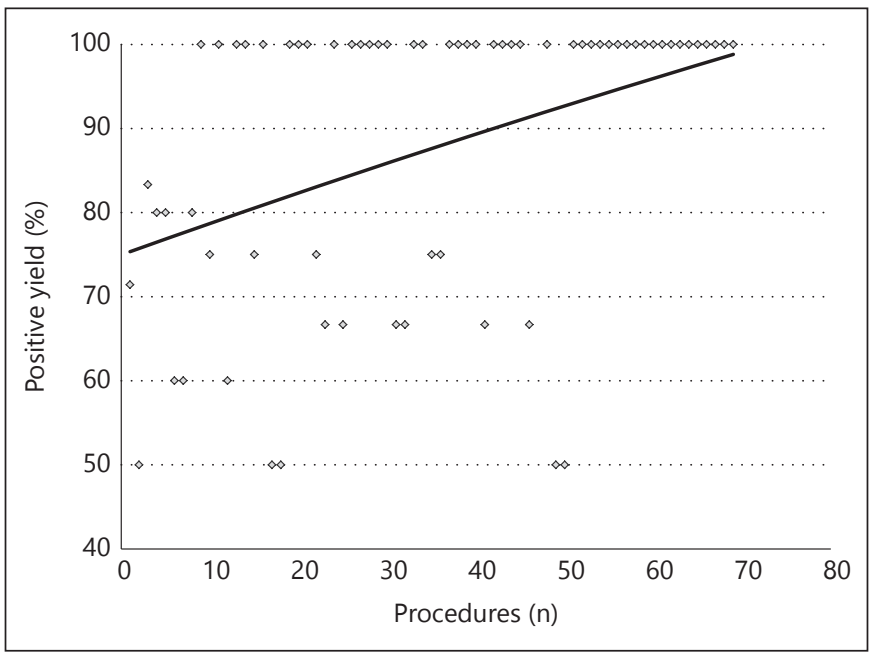

Fig. 1. Attending physicians' learning curve for EBUS-TBNA: yield steadily rises with each procedure performed by attending physicians.

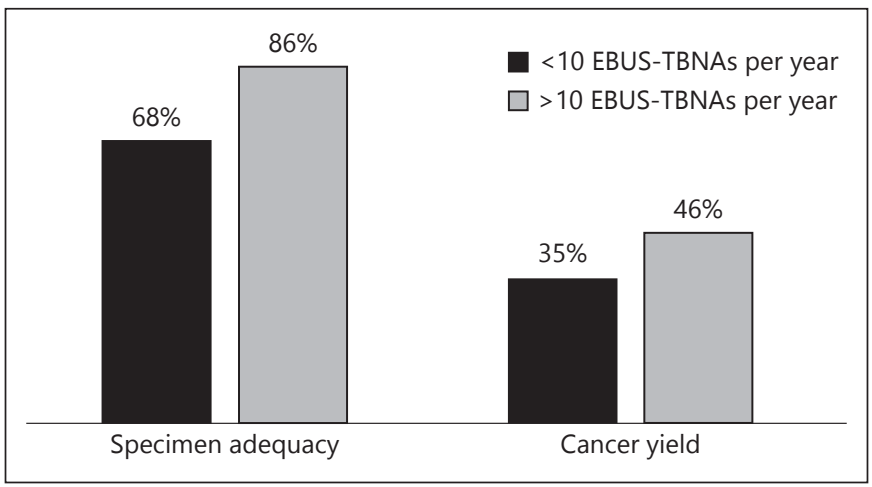

Fig. 2. Yield by number of EBUS-TBNA performed each year. Specimen adequacy $(\mathrm{p}=0.01)$ and cancer yield $(\mathrm{p}<0.01)$ are statistically significantly better among attending physicians performing $>10$ procedures per year.

Table 2. Lymph node characteristics

\begin{tabular}{lcl}
\hline ATS station & $\%(\mathrm{n})$ & Node size, $\mathrm{mm}$ \\
\hline $2 \mathrm{~L}$ & $1 \%(2)$ & $13 \pm 1$ \\
$2 \mathrm{R}$ & $4 \%(15)$ & $13 \pm 6$ \\
$4 \mathrm{~L}$ & $9 \%(32)$ & $15 \pm 4$ \\
$4 \mathrm{R}$ & $38 \%(130)$ & $17 \pm 8$ \\
7 & $25 \%(86)$ & $16 \pm 7$ \\
$10 \mathrm{~L}$ & $2 \%(6)$ & $24 \pm 12$ \\
$10 \mathrm{R}$ & $6 \%(22)$ & $15 \pm 5$ \\
$11 \mathrm{~L}$ & $1 \%(5)$ & $21 \pm 6$ \\
$11 \mathrm{R}$ & $11 \%(38)$ & $16 \pm 6$ \\
Mean & & $16 \pm 7$ \\
\hline
\end{tabular}

ATS $=$ American Thoracic Society. Means \pm SD and $\%$ (n). $\min , 2012$ : mean $86 \pm 17 \mathrm{~min}, \mathrm{p}=0.12$ ) or procedure time (2008: mean $38 \pm 12$ min, 2012: mean $48 \pm 20$ min, $p=$ 0.63 ; table 1). Procedure time was shorter when the advanced bronchoscopy fellow was the primary operator ( $38 \pm 14$ vs. $43 \pm 16$ min, $\mathrm{p}<0.05$ ).

\section{Lymph Node Characteristics}

Of the 222 EBUS-TBNAs performed, 344 nodes were biopsied (1.5 nodes per procedure). There was an increase in the number of nodes sampled per procedure from 2008 to 2012 (from 1.3 to 1.6). Nodal stations biopsied were 4R (38\%), 7S (25\%), 11R (11\%), 4L (9\%) and $10 \mathrm{R}(6 \%)$. The number of hilar nodes aspirated increased from $13 \%$ in 2008 to $34 \%$ in 2012 ( $\mathrm{p}<0.01$ ). Mean node size biopsied was $16 \pm 7 \mathrm{~mm}$ (table 2 ).

\section{Pathology and Diagnosis}

Cytopathology of the lymph node aspirates revealed an improvement in yield over time. Cancer yield increased from $34 \%$ in 2008 to $48 \%$ in 2012 ( $p<0.01$ ). The majority of malignant aspirates were non-small cell carcinomas (74\%). Small cell lung cancer comprised $13 \%$ of the samples. Lymphoid tissue indicating successful nodal sampling but without a pathologic diagnosis was seen in $28 \%$ of the EBUS-TBNAs. Overall, 14\% of EBUS-TBNAs had an unsatisfactory sample (not representative of nodal tissue), but that frequency decreased over time (from $24 \%$ in 2008 to $7 \%$ in $2012, \mathrm{p}=0.17$ ). Adequate specimens, in which either a diagnostic specimen or lymphoid tissue was obtained, were retrieved in $83 \%$. Larger nodes tended to have higher cancer yields; mean node size for malignancy was $19 \pm 8 \mathrm{~mm}$ compared to $14 \pm 5 \mathrm{~mm}$ for nonmalignant and unsatisfactory samples $(\mathrm{p}<0.01)$. Adequate specimen retrieval increased from $66 \%$ in 2008 to $90 \%$ in 2012 (p < $0.01)$. Use of general anesthesia was associated with higher adequate specimen retrieval (78\% for moderate sedation vs. $85 \%$ for general anesthesia, $\mathrm{p}<0.01)$ and sampling of smaller nodes ( $18 \pm 8$ vs. $15 \pm 7 \mathrm{~mm}, \mathrm{p}=0.02)$. Cancer yield did not differ with the type of sedation ( $45 \%$ for moderate sedation vs. $44 \%$ for general anesthesia, $\mathrm{p}=0.40$ ).

\section{EBUS Learning Curve}

EBUS-TBNA yield varied with operator experience. For attending bronchoscopists, overall yield improved with every 25 procedures: from 78 to 87 to $90 \%$ (fig. $1 ; \mathrm{p}<$ 0.01 ). Bronchoscopists who performed on average more than 10 EBUS per year had a higher specimen adequacy ( 85 vs. $68 \%, p=0.01)$ and cancer yield ( 46 vs. $35 \%, \mathrm{p}<$ 0.01 ; fig. 2). Trainees of every year of fellowship were allowed to perform the procedure with direct attending su- 


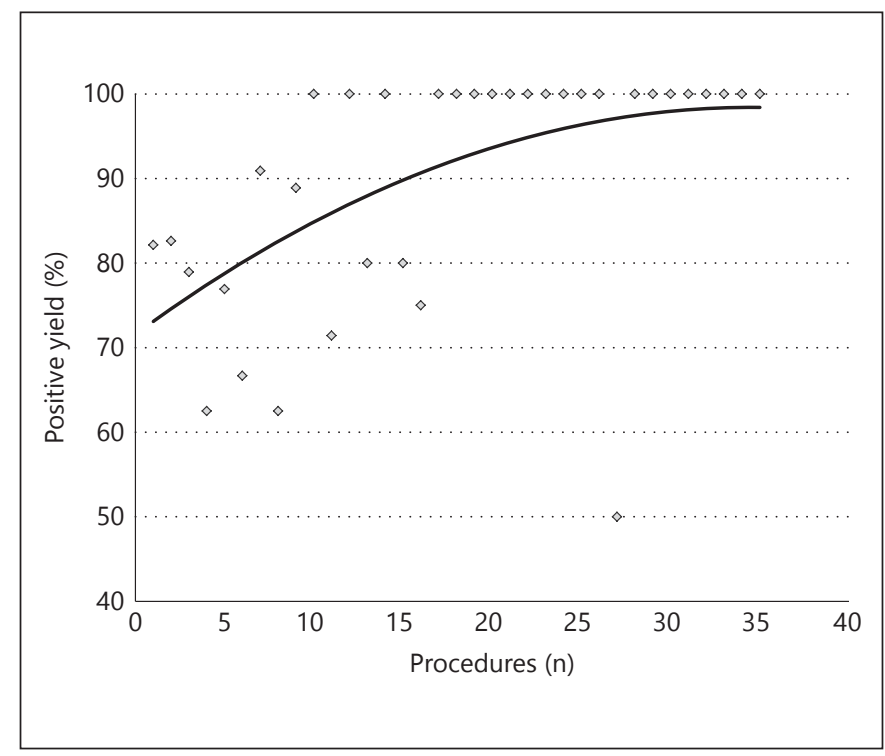

Fig. 3. Trainee learning curve with EBUS-TBNA: yield steadily rises with each procedure performed by trainees.

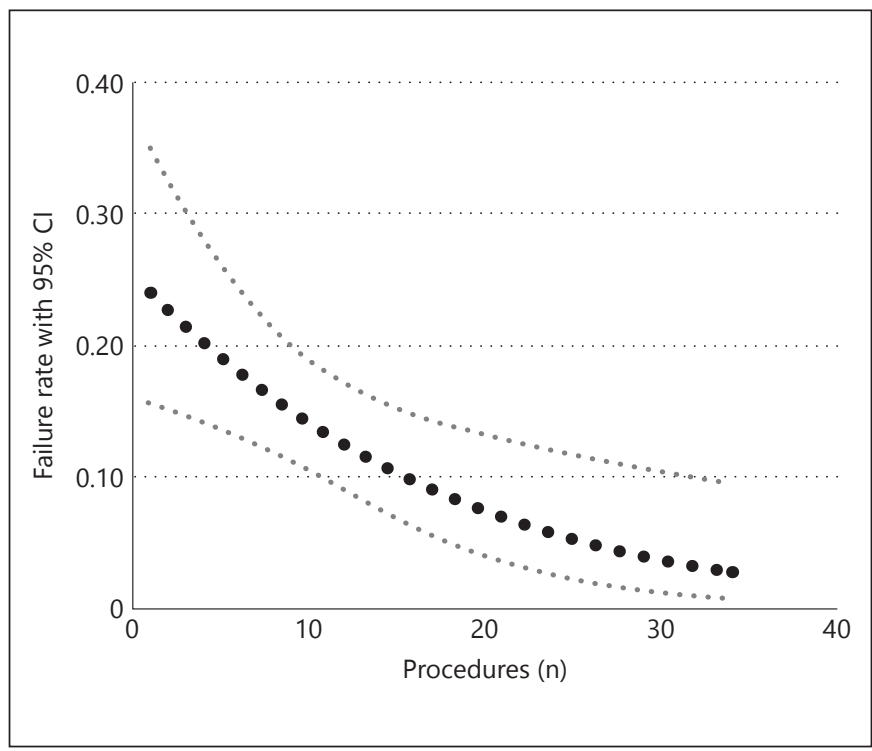

Fig. 4. Fall in failure rate among trainees with each EBUS-TBNA performed. Unadjusted $\mathrm{p}=0.02$. When adjusted for the type of sedation, average node size and year the procedure was performed, the fall in the failure rate is still statistically significant $(\mathrm{p}=0.05$, 95\% CI 0.889-1.000).

Table 3. Yield by procedure number

\begin{tabular}{|c|c|c|c|c|c|c|c|c|}
\hline $\begin{array}{l}\text { Procedures } \\
\text { performed }\end{array}$ & \multicolumn{4}{|l|}{ Attending } & \multicolumn{4}{|l|}{ Trainees } \\
\hline $1-10$ & 8 & 53 & 70 & & 25 & 146 & 79 & \\
\hline $11-20$ & 5 & 43 & 84 & 0.11 & 10 & 48 & 90 & 0.08 \\
\hline $21-30$ & 4 & 32 & 94 & $<0.01$ & 3 & 19 & 95 & 0.06 \\
\hline $51-60$ & 2 & 12 & 100 & $<0.01$ & & & & \\
\hline
\end{tabular}

pervision. First-year trainees performed $24 \%$ of procedures, 2nd-year fellows performed $31 \%$ of procedures and 3rd-year trainees performed $44 \%$ of procedures. Yield improved with each year of training: 1 st: $79 \%$ adequate $/ 44 \%$ cancer, 2 nd: $84 \%$ adequate $/ 43 \%$ cancer, 3 rd: $85 \%$ adequate $/ 48 \%$ cancer ( 1 st vs. 3 rd year, $\mathrm{p}<0.01$ for specimen adequacy and $\mathrm{p}=0.01$ for cancer yield). Individual trainees improved their yield after every 10 procedures: from $79 \%$ (41\% cancer yield) to $90 \%$ (54\% cancer yield) to $95 \%$ ( $58 \%$ cancer yield; $\mathrm{p}<0.01$ for adequacy and $\mathrm{p}=0.03$ for cancer yield; fig. 3; table 3 ). An advanced bronchoscopy fellow was the primary operator in almost half of the procedures (46\%), and his/her yield was high- er than that of other trainees ( 88 vs. $79 \%, \mathrm{p}<0.01)$. The difference was not due to an increase in cancer yield (52 vs. $48 \%, \mathrm{p}=0.76$ ) but rather to fewer unsatisfactory samples ( $10 \%$ for the advanced bronchoscopy fellows vs. $18 \%$ for other fellows, $\mathrm{p}=0.05$ ).

Failure rates - defined as insufficient or unsatisfactory samples according to cytopathology - were analyzed using a generalized linear model. Rising procedural numbers correlated with falling failure rates $(\mathrm{p}=0.02$; fig. 4$)$. When adjusted for the type of sedation, average node size and year the procedure was performed, the fall in failure rate remained statistically significant $(\mathrm{p}=0.05,95 \% \mathrm{CI}$ 0.889-1.000). 


\section{Discussion}

The overall EBUS-TBNA yield in this report is consistent with that at skilled centers (89-95\%) [3-6]. The cancer yield and specimen adequacy improved with experience. Yields rose over 5 years with increasing institutional experience. The bronchoscopists who performed more EBUS per year had higher yields than those who performed fewer procedures, consistent with previously described learning curves for EBUS-TBNA and other bronchoscopic sampling procedures $[12,17,18]$. Yield improved significantly after 20 and 25 bronchoscopies among trainees and skilled bronchoscopists, respectively. Yield rose with each trainee year, and the advanced bronchoscopy trainee achieved higher specimen adequacy with shorter procedure time compared to other trainees. Failure rates declined with each procedure performed. This study is consistent with the range of other demonstrations of learning curves ranging from 10 to 50 procedures [9-12], but this study is the first to analyze the performance of both experienced bronchoscopists and trainees over a prolonged time. Similar to other reports, use of general anesthesia correlated with improved lymph node sampling $[17,19]$.

The number of procedures performed over this 5-year review $(n=222)$ is less than some centers perform over the course of 1 year. This is because we reserve EBUS for sampling of smaller nodes and cancer staging (mean $16 \pm$ $7 \mathrm{~mm}$, median $14 \mathrm{~mm}$ ). Larger adenopathy and masses are sampled with cTBNA ( $\mathrm{n}=209$ from 2009 to 2010) as our yield with this modality when targeting larger nodes is high ( $86 \%$ yield, mean size $21 \pm 11 \mathrm{~mm}$ ) [16]. Using the complementarity of cTBNA and EBUS spares patients the higher cost of EBUS [16, 20]. Reserving smaller nodes and staging for EBUS may explain why our yields are lower than at some centers. If EBUS were used in 'all comers' with mediastinal and hilar lymphadenopathy we would anticipate higher EBUS yields. We did not appraise the effects of trainee familiarity and performance of cTBNA upon their EBUS learning curves nor did we evaluate the impact of virtual reality simulation $[21,22]$. Each of these factors might further enhance trainee EBUS performance.

This retrospective study is limited in that we cannot divide which samples were specifically obtained by the trainee and which samples were obtained by the attending bronchoscopist. It is our practice that we gradually give advancing fellows more independence. Attending physicians are more likely to sample concurrently with 1st- and 2nd-year trainees, while they may observe 3rd-year trainees and the advanced bronchoscopy fellow without taking the bronchoscope. Since we use on-site cytology, attending physicians are more likely to participate in specimen acquisition if the first few passes are negative.

The progressive increase in yield in EBUS-TBNA is similar to that observed with cTBNA (i.e. guided by preprocedural computed tomography rather than real-time imaging). Malignancy yields improved from 21 to $48 \%$ over a 3-year review after increasing procedural volume, trainee education and alterations in aspiration techniques [20]. Following initiation of cTBNA, Hsu et al. [23] reported improved yields over a 3.5-year period $(\mathrm{p}=0.03)$. After analyzing yields of TBNA, another site concluded that 50 procedures were required to achieve proficiency [24], while other facilities improved yield from 19 to $88 \%$ $(\mathrm{p}<0.001)$ [25] and 46 to $85 \%(\mathrm{p}=0.09)$ [26] over an 18 -month and 1-year self-learning period, respectively. Hermens et al. [27] reported improved TBNA yields from 77 to $87 \%$ after 32 months of experience. More recently, another center demonstrated yields improving from 72 to $96 \%$ after an observational education program [28]. A systematic review of cTBNA revealed that sensitivity rose with rising bronchoscopist experience [29].

Our study has important implications for training and credentialing. While the yield was higher for the advanced bronchoscopy fellow, this training was not essential to achieving acceptable EBUS yields. As part of their comprehensive education, we emphasize the need for all bronchoscopy trainees to learn EBUS.

\section{Conclusions}

In an academic environment with intense supervision and training and established use of conventional TBNA, EBUS-TBNA yield improves after 20 and 25 procedures in experienced bronchoscopists and trainees, respectively. Failure rates declined with each trainee procedure. Our data and other studies suggest that a minimum of 20-25 procedures are needed to significantly raise yields. This is below the minimum of 50 recommended by the American College of Chest Physician expert opinion guidelines for competency [7]. In addition, these data suggest that maintenance of procedural skills for EBUSTBNA may be at least 10 procedures per year to preserve higher yields.

\section{Disclosure Statement}

No conflicts of interest. 


\section{References}

1 Gompelmann D, Herth FJF: Role of endobronchial and endoscopic ultrasound in pulmonary medicine. Respiration 2014;87:3-8.

$\checkmark 2$ Becker HD: EBUS: a new dimension in bronchoscopy. Respiration 2006;73:583-586.

$\checkmark 3$ Herth F, Becker DH, Ernst A: Conventional vs endobronchial ultrasound-guided transbronchial needle aspiration: a randomized trial. Chest 2004;125:322-325.

4 Plat G, Pierard P, Haller A, et al: Endobronchial ultrasound and positron emission tomography positive mediastinal lymph nodes. Eur Respir J 2006;27:276-281.

5 Yasufuku K, Chiyo M, Sekine Y, et al: Realtime endobronchial ultrasound-guided transbronchial needle aspiration of mediastinal and hilar lymph nodes. Chest 2004;126:122128.

6 Vincent BD, El-Bayoumi E, Hoffman B, et al: Real-time endobronchial ultrasound-guided transbronchial lymph node aspiration. Ann Thorac Surg 2008;85:224-230.

$>7$ Ernst A, Silvestri GA, Johnstone D: Interventional pulmonary procedures: guidelines from the American College of Chest Physicians. Chest 2003;123:1693-1717.

$>8$ Kemp SV, El Batrawy SH, Harrison RN, et al: Learning curves for endobronchial ultrasound using cusum analysis. Thorax 2010;65: 534-538.

$>9$ Steinfort DP, Hew JM, Irving LB: Bronchoscopic evaluation of the mediastinum using endobronchial ultrasound: a description of the first 216 cases carried out at an Australian tertiary hospital. Intern Med J 2011;41:815824.

10 Groth SS, Whitson BA, D’Cunha J, Maddaus M, Alsharrif M, Andrade RS: Endobronchial ultrasound-guided fine-needle aspiration of mediastinal lymph nodes: a single institution's early learning curve. Ann Thorac Surg 2008;86:1104-1110.
$11 \mathrm{Hu}$ Y, Puri V, Crabtree TD, et al: Attaining proficiency with endobronchial ultrasoundguided transbronchial needle aspiration. J Thoracic Cardiovasc Surg 2013;146:13871392.

12 Wahidi MM, Hulett C, Pastis N, et al: Learning experience of linear EBUS among pulmonary trainees. Chest 2014;145:574-578.

13 Folch E, Majid A: Point: are >50 supervised procedures required to develop competency in performing endobronchial ultrasoundguided transbronchial needle aspiration for mediastinal staging? Yes. Chest 2013;143: 888-891.

14 Kinsey MC, Channick CL: Counterpoint: are $>50$ supervised procedures required to develop competency in performing endobronchial ultrasound-guided transbronchial needle as piration for mediastinal staging? No. Chest 2013;143:891-893.

$>15$ Bellinger C, Chatterjee A, Chin R, Conforti J, Adair N, Haponik E: Conventional and endobronchial ultrasound-guided transbronchial needle aspiration (TBNA): complementary procedures. South Med J 2012;105:625-629.

-16 Mirsadraee S, Oswal D, Alizadeh Y, Caulo A, van Beek EJR: The 7th lung cancer TNM classification and staging system: review of the changes and implications. World J Radiol 2012;4:128-134.

17 Ost DE, Ernst A, Feller-Kopman D, et al: Diagnostic yield of endobronchial ultrasoundguided transbronchial needle aspiration: results of the AQuIRE Bronchoscopy Registry. Chest 2011;140:1557-1566.

18 Haponik EF, Cappellari JO, Chin R, et al: Education and experience improve transbronchial needle aspiration performance. Am J Respir Crit Care Med 1995;151:1998-2002.

19 Yarmus LB, Akulian JA, Gilbert C, et al: Comparison of moderate versus deep sedation for endobronchial ultrasound transbronchial needle aspiration. Ann Am Thorac Soc 2013; 10:121-126.
20 Mehta AC, Wang KP: Teaching conventional transbronchial needle aspiration. Ann Am Thorac Soc 2013;10:685-688.

21 Stather DR, MacEachern P, Rimmer K, Hergott CA, Tremblay A: Validation of an endobronchial ultrasound simulator: differentiating operator skill level. Respiration 2011;81: 325-332.

22 Konge L, Annema J, Clemensten P, Minddal V, Vilmann P, Ringsted C: Using virtual reality simulation to assess performance in endobronchial ultrasound. Respiration 2013;86: 59-65.

23 Hsu L, Liu C, Ko J: Education and experience improve the performance of transbronchial needle aspiration: a learning curve at a cancer center. Chest 2004;125:532-540.

24 Rodriquez de Castro F, Diaz Lopez F, Serda GJ, Lopez AR, Gilbert JF, Cabrera Narro P Relevance of training in transbronchial fineneedle aspiration technique. Chest 1997;111: 103-105.

25 Raveglia F, Meda S, Conforti S, et al: Diagnostic value and learning curve of transbronchial needle aspiration in thoracic surgery. Minerva Chir 2006;61:459-466.

26 Boonsarngsuk V, Pongtippan A: Self-learning experience in transbronchial needle aspiration in diagnosis of intrathoracic lymphadenopathy. J Med Assoc Thai 2009;92:175-181.

27 Hermens FH, Limonard GJ, Termeer R, et al: Learning curve of conventional transbronchial needle aspiration in pulmonologists experienced in bronchoscopy. Respiration 2008;75: 189-192.

28 Tutar N, Buyukglan H, Yilmaz I, et al: Learning curve of conventional transbronchial needle aspiration. Clin Respir J 2013;8:79-85.

29 Bonifazi M, Zucctosat L, Trisolini R, Moja L, Gasparini S: Transbronchial needle aspiration: a systematic review on predictors of a successful aspirate. Respiration 2013;86:123-134. 